\title{
School bus routing problem considering affinity among children
}

\section{Juan Pablo Orejuela Cabrera ${ }^{a}$, Milton Alexander Londoño ${ }^{b}$ and Vivian Lorena Chud Pantoja ${ }^{a^{*}}$}

\author{
${ }^{a}$ School of Industrial Engineering, Universidad del Valle, Colombia \\ ${ }^{b}$ Universidad del Valle, Colombia \\ 'Ingeniería Industrial, Universidad del Valle Sede Zarzal, Colombia \\ C H R O N I C L E \\ Article history: \\ Received January 20, 2021 \\ Received in revised format: \\ April 14, 2021 \\ Accepted April 272021 \\ Available online \\ April 27, 2021 \\ Keywords: \\ School bus routing problem \\ Affinity assignment \\ Social aspects in the SBRP

\begin{abstract}
A B S T R A C T
School bus routing problem is widely studied, however, social elements such as the interaction between children traveling on the same route have not been considered so far. In this way, this article has as its main objective to propose a methodology to solve the school bus routing problem, including affinity as a strategy to increase positive interrelationships between children, and with this, support in bullying situations during school trips. The methodology includes two stages, assigning children to vehicles considering affinities and defining vehicle routes. The main contribution is the consideration of affinity in the process of forming the groups of children that will be taken on the bus, evidencing a balance in the affinity of the groups. Additionally, from the methodological point of view, the integration of a modified group technology algorithm and a new assignment model are proposed that simplify the classic quadratic assignment problem. Consideration of affinity in school bus routing generates benefits from a social point of view.
\end{abstract}

\section{Introduction}

The school bus routing has its own set of elements in addition to its complexity as an extension of the problem of vehicle routing that makes it especially unique; this includes the transport of children who socially interact inside the bus and at the bus stops. These interactions are recognized as important to the educational process of the child; however, they present some difficulties, for example, when some of the children are insensitive to the suffering of their classmates and bullying arises. Studies show that bullying goes beyond the limits of schools and extends to environments such as school buses (Galliger et al., 2009), yet these environments have received little attention so far (Goodboy et al., 2016). Bullying and school violence include psychological, physical and sexual violence, carried out mainly by classmates at school or college (UNESCO, 2018). Bullying has a significant impact on mental health, quality of life, and risk behaviors (UNESCO, 2019). In Colombia in 2012 (Jiménez, 2018), it was reported that 40 out of 100 students dropped out of school; apparently, the main cause was related to the abuse they received from their classmates. Faced with this problem, there are different studies that analyze the efforts of intervention and prevention of bullying in schools (Goodboy et al., 2016). However, although there is evidence for the negative consequences of school bullying, there is no consensus on the most effective strategies to combat this problem (Gutierrez \& Nopo, 2018). Specifically, in school bus bullying (Raskauskas, 2005), it was found that an average of two bullying incidents occurred per bus trip. Given the problems that arise in the school bus and at bus stops, it is necessary to consider strategies that contribute to the prevention of bullying in these environments since conflicts on buses affect not only the environment in general but also the driver's concentration (Goldman \& Peleg, 2010). In the development of bullying prevention strategies, the consideration of the behavior of students who witness these behaviors is key to reducing incidents since these students can intervene by defending or consoling those who are bullied (White, 2019). In (Craig \& Pepler, 2007), it is mentioned that interventions to counteract bullying focus, among other aspects, on supporting positive interactions between children and that these should be extended to areas outside the classroom.

\footnotetext{
* Corresponding author.

E-mail address: vivian.chud@correounivalle.edu.co (V. L. C. Pantoja)

(C) 2021 by the authors; licensee Growing Science, Canada.

doi: $10.5267 /$ j.dsl.2021.5.002
} 
In the present research, in light of what was indicated in (Long et al., 2015), it is proposed to maximize the affinity between students traveling on the same route to strengthen and stimulate positive interactions and thereby reduce the risk of bullying in the school transportation environment.

Initially, the school bus routing problem, the concepts of grouping children for school bus routing, and the consideration of the affinity of children in their bus assignment are presented within the frame of reference. Subsequently, the methodology, results, discussion, and conclusions are presented.

\section{Frame of reference}

\subsection{The school bus routing problem}

The school bus routing problem (SBRP) seeks to transport a number of children $i$ living in different points in a city to their school (Sarubbi et al., 2016) (Fig. 1). For this task, $k$ vehicles pick up children from their homes or assigned stops and take them to school (Unsal et al., 2016).

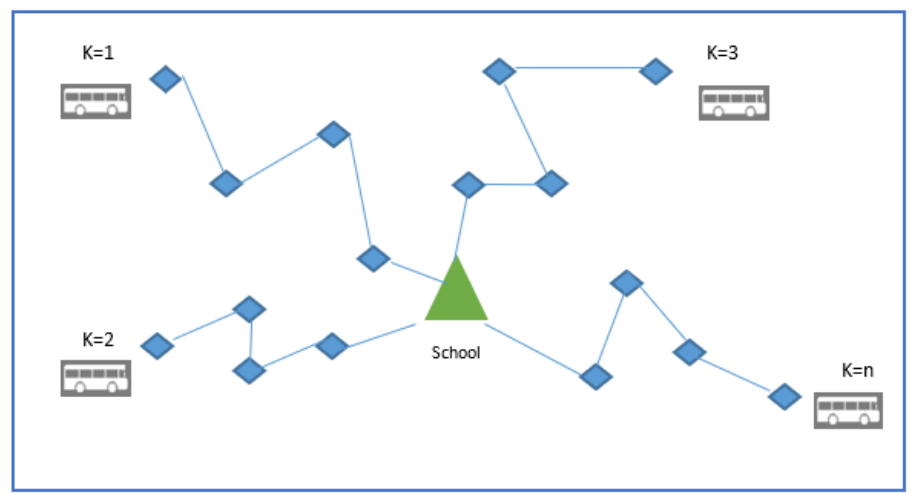

Fig. 1. General representation of the school bus routing problem

There are different approaches to solving the vehicle routing problem. One of the commonly used approaches, given the complexity of these problems, is the hierarchical approach (Comert et al., 2018), in which the most complex problem is decomposed into less complex subproblems that can be solved by different techniques. There are two general strategies in this approach, assign first - route later (Miranda-Bront et al., 2017) and route first - assign later (Emilia \& Emilia, 1983). The first is widely used by the authors (Duque Correa \& Baldoquín de la Peña, 2018) and is used in this study because it is intended to explore affinity, which is defined in the first phase of assignment. Initially, children to be transported are assigned to each vehicle, and then the pickup route to school is defined. The two subproblems are presented in Fig. 2.

\begin{tabular}{|l|l|}
\hline \multicolumn{1}{|c|}{ Subproblem 1 } & \multicolumn{1}{c|}{ Subproblema 2} \\
\hline $\begin{array}{l}\text { - Grouping children } \\
\text { - Assigning children to buses }\end{array}$ & $\bullet$ Definition of routes \\
\hline
\end{tabular}

Fig. 2. Subproblems of the school bus routing problem

Generally, the assignments of children to buses are based on a shorter trip or lower cost; however, this research seeks to maximize the affinity between the children who ride the same bus.

According to what is stated in (Ellegood et al., 2019), research in the subject of SBRP should focus on the development of models that incorporate social and cultural factors. In this sense, this article seeks to contribute to this field of work, including the affinity between children as a social dimension in the SBRP, which in turn contributes as reinforcement mechanisms for positive relationships, a key factor in bullying prevention.

Additionally, note that affinity between people has been studied in the literature as a social strategy to improve performance and well-being in the process of forming work teams, especially in research related to room scheduling in hospitals (Meskens et al., 2013), in the definition of air routes where crew preferences or constraints are established (Kohl \& Karisch, 2004), and in defining crew rostering in service companies (Lin et al., 2012). However, thus far, no studies have considered the affinity between children in the SBRP, which is the main contribution of the present investigation. 


\subsection{Grouping and affinity in the school bus routing}

As proposed in (Long et al., 2015), the grouping of children for school bus routing should consider social grouping, in which the individuals linked in the process share some attributes; in other words, there is affinity between the children. This aspect becomes relevant when assigning children to a bus or a transportation route for school since it ensures the reinforcement of positive relationships between children and aims for greater satisfaction in the trip (Fig. 3).

Social grouping can arise from a combination of processes that includes homophily, that is, the tendency of people to choose individuals who have similar traits as friends. Secondary homophily, which refers to a different measurable shared trait, can also be used (Long et al., 2015). This article mainly considers homophily, where it is expected that children prefer to travel with their friends.

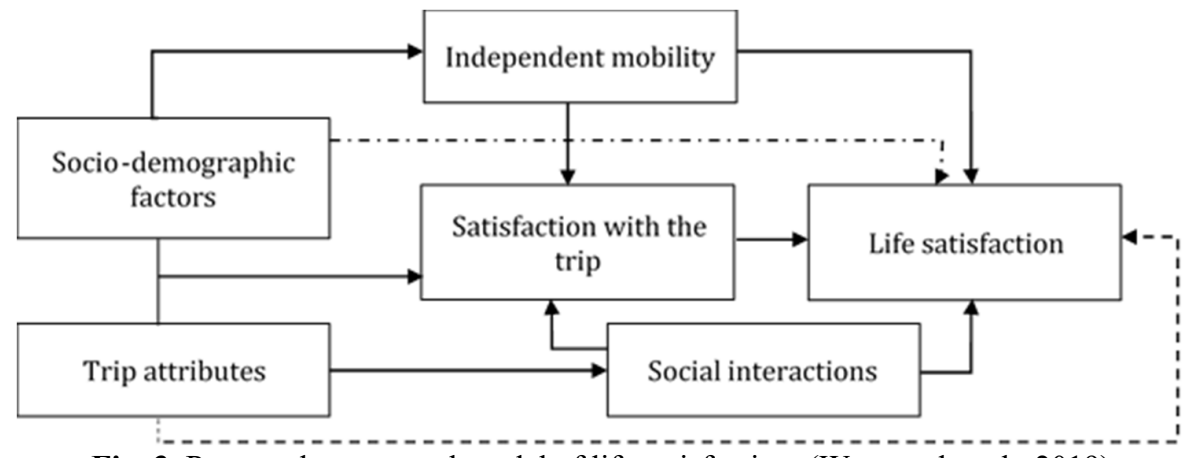

Fig. 3. Proposed conceptual model of life satisfaction. (Waygood et al., 2019)

Some studies that consider the affinity between people in forming teams, such as (Meskens et al., 2013), where affinity is used to form efficient surgical teams by establishing an affinity matrix between surgeons, anesthetists, and nurses who all indicated who they preferred to work with as well as any existing incompatibilities between them, have been identified. Likewise, in (Lin et al., 2012), linear programming of a mathematical model of objectives for the assignment of personnel in a customer service section, which includes a compatibility function between workers that is measured according to Saaty's scale proposed in (Saaty, 1987), was developed.

Additionally, the scheduling problem of personnel in transportation has been identified, known as the crew scheduling problem (Kumar et al., 2010). This generally includes the consideration of two subproblems: the first corresponds to the pairing of the crew and the second is related to the assignment of the crew (Kasirzadeh et al., 2017), where tasks are assigned to the crew members according to their preferences or at least guaranteeing an equitable distribution of the perceived prejudices, aiming for job satisfaction (Kumar et al., 2010).

With regard to the vehicle routing problem, some authors have considered user preferences in shared transport systems. In (Aiko et al., 2018), a vehicle routing optimization model was developed that considers the preferences of the users who will share the transport; for this, the authors used mixed integer quadratic programming and pointed out that the personal preference of a user in relation to their other travel companions represents an important factor in shared travel systems. Additionally, (Thaithatkul et al., 2015) developed a coincidence model in shared travel systems, where personal preference is included as the user preference for passenger's personalities. They established the problem of steadiness of user personality and modified it with the problem of correspondence between passengers. On the other hand, among the most common methods for forming clusters in the vehicle routing problem is the Clarke and Wright savings method, which seeks to minimize the distance traveled to satisfy demand (Clarke \& Wright, 1964). There is also the sweep line algorithm, which generates clusters by rotating a ray with the origin at the depot, sweeping the customers within reach and incorporating them into the group until the vehicle capacity is reached (Gillett \& Miller, 1974a)(Quintero Quintero, 2012). Another grouping technique is the propagation of the coefficient, in which the way in which customers join the cluster is defined by the association of depot attraction coefficients and customers already assigned (Giosa et al., 2017). Additionally, with the p-median method, the centers of the clusters can be chosen in a way that minimizes the sum of the Euclidean distances of the objects assigned to each center (Brusco, M.J., Köhn, 2008). Likewise, the k-means clustering algorithm separates $n$ objects into $\mathrm{k}$ groups, minimizing the sum of the distances between the assigned objects and the center of their group (MacQueen \& Others, 1967).

\section{Materials and methods}

The methodology has two phases (Fig. 4). In the first, the children are assigned to the vehicles. Once the groups of children who will travel in each vehicle are obtained, the second phase is developed, defining the route of each vehicle. Considering each of the groups formed in the phase above, a traveling salesman problem (TSP) model is used for each vehicle. Finally, the model is validated through a case study. 


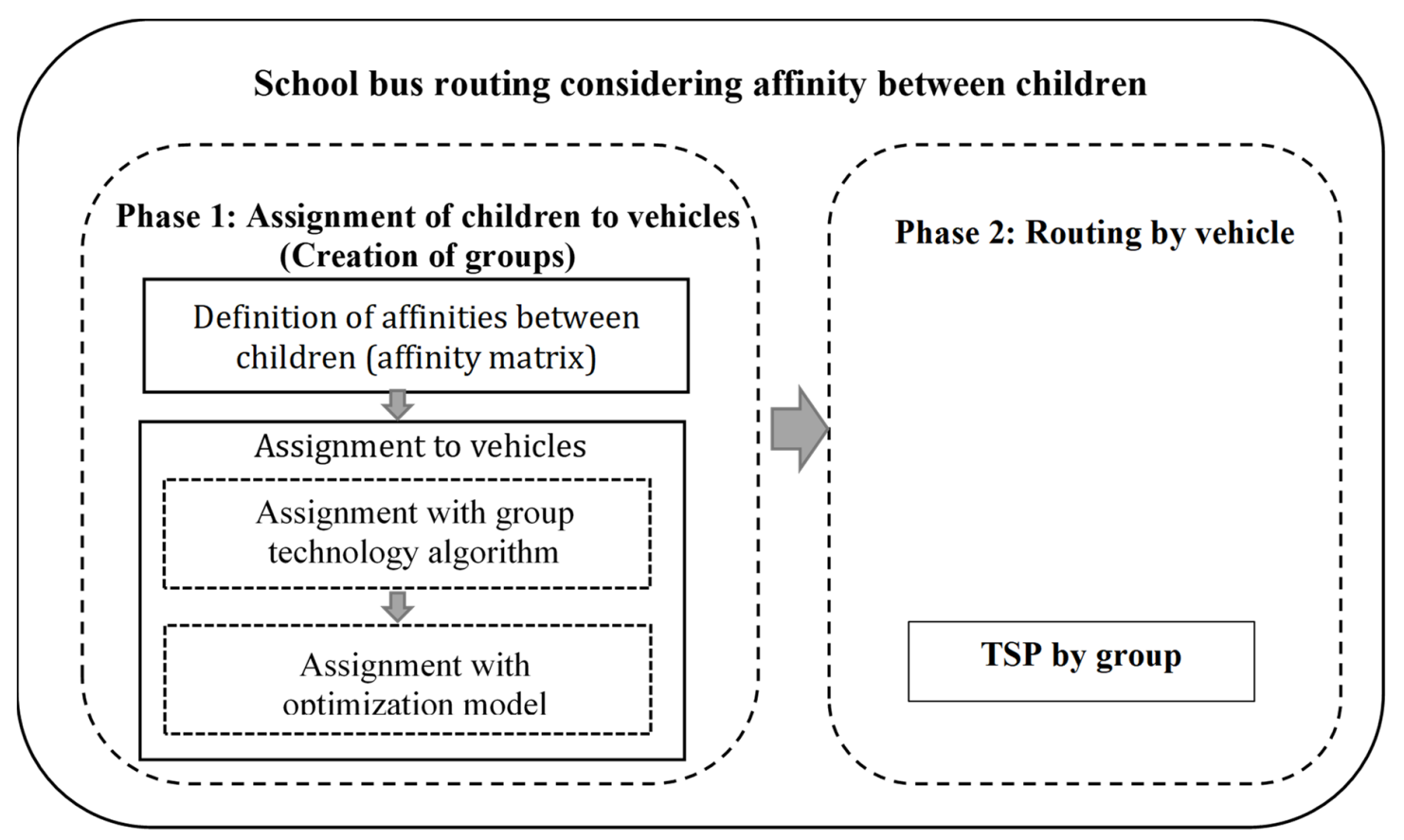

Fig. 4. Phases of the proposed methodology for the school bus routing considered

\subsection{Phase 1. Assignment of children to vehicles}

\subsubsection{Definition of the affinity between children}

It is considered that child $i$ has an affinity with classmate $j$, where $i=1,2,3 \ldots N$ and $N$ is the total number of children. The affinity can be represented as the minimum (aij, aji) as proposed in (Lin et al., 2012). In this case, the scale proposed by Saaty is considered (Saaty, 1987), adjusted as in Table 1, where 1 represents low affinity and 9 represents extreme affinity.

Table 1.

Assessment scale for the degree of affinity that a child has with a classmate

\begin{tabular}{cc}
\hline Intensity of affinity & Definition \\
\hline 1 & Low affinity \\
3 & Moderate affinity \\
5 & Strong affinity \\
7 & Very strong affinity \\
9 & Extreme affinity
\end{tabular}

Adapted from (Lin et al., 2012)

To determine the general affinity matrix, Aij denotes the quadratic matrix resulting from comparing affinity aij with aji. In the case in which these affinities are not symmetrical, the lowest affinity between the two is selected, as proposed in (Meskens et al., 2013).

\subsubsection{Assignment of children to school buses}

The affinity between two children must be calculated when the two children are in the same vehicle. In this sense, the traditional representation of this problem is posed as a quadratic assignment problem (QAP), in which the binary variable Yik is used to define whether child $i$ is assigned to vehicle $k$, and the affinity between child $i$ and child $j$ would be determined in the model as Yik* Yjk* Aij, such that only when both binaries are worth one is the value of the affinity determined.

QAP models are complex (Zhou et al., 2017), and the nonlinearity between their variables means that they can be used only to solve small instances common in floor distribution problems. However, in an affinity problem associated with the SBRP, as is the case in this research, the number of children in a school can be approximately 400 , and between $30 \%$ and $40 \%$ use school transportation. This generates a significant number of children for the affinity problem, exceeding the response times of the QAP models. 
In this sense, a mathematical model is proposed for the assignment that measures the affinity with a linear performance function, and a preassignment algorithm is added to reduce the complexity and computational time. Two stages are developed to address the assignment process, where a percentage of children with greater affinity are assigned using a group technology (GT) algorithm and the percentage of remaining children are assigned with the proposed linear mathematical optimization model, which simplifies the quadratic assignment process, representing the methodological contribution in this research.

\subsubsection{Assignment using the group technology algorithm}

An algorithm based on GT is proposed (Kalpakjian \& Steven, 2008) for grouping children who have similar characteristics, that is, based on the affinity matrix of the children. Fig. 5 shows the proposed algorithm, which is based on the GT algorithm presented in (Sule, 2001).

Initially, $n$ is defined as the number of children; $c$ as the vehicle capacity; $g$ as the number of groups; $\alpha$ as the threshold of acceptance of a child in the group; Aij as the affinity matrix of children $i, j ; \mathrm{VA}_{\mathrm{w}}$ as the affinity vector of the ranked pairs of children $i, j$, where $\mathrm{w}$ is the index of the pairs ranked from highest to lowest affinity; $P$ as the percentage of children to be assigned with the GT algorithm, where the remaining percentage is $1-P$, which is assigned with a mathematical model to obtain better performance measures; $Q$ as the percentage of the vehicle capacity to be assigned by the algorithm; $n a$ as the list of children to be assigned with the algorithm; $v$ as the number of vehicles; and $n g$ as the number of children in the group. The affinity or relationship $r$ of an unassigned child is calculated in Eq. (1):

$$
r=\frac{\sum_{\mathrm{i}=1}^{n g} A_{e, i}}{n g}, e=\text { unassigned child }
$$

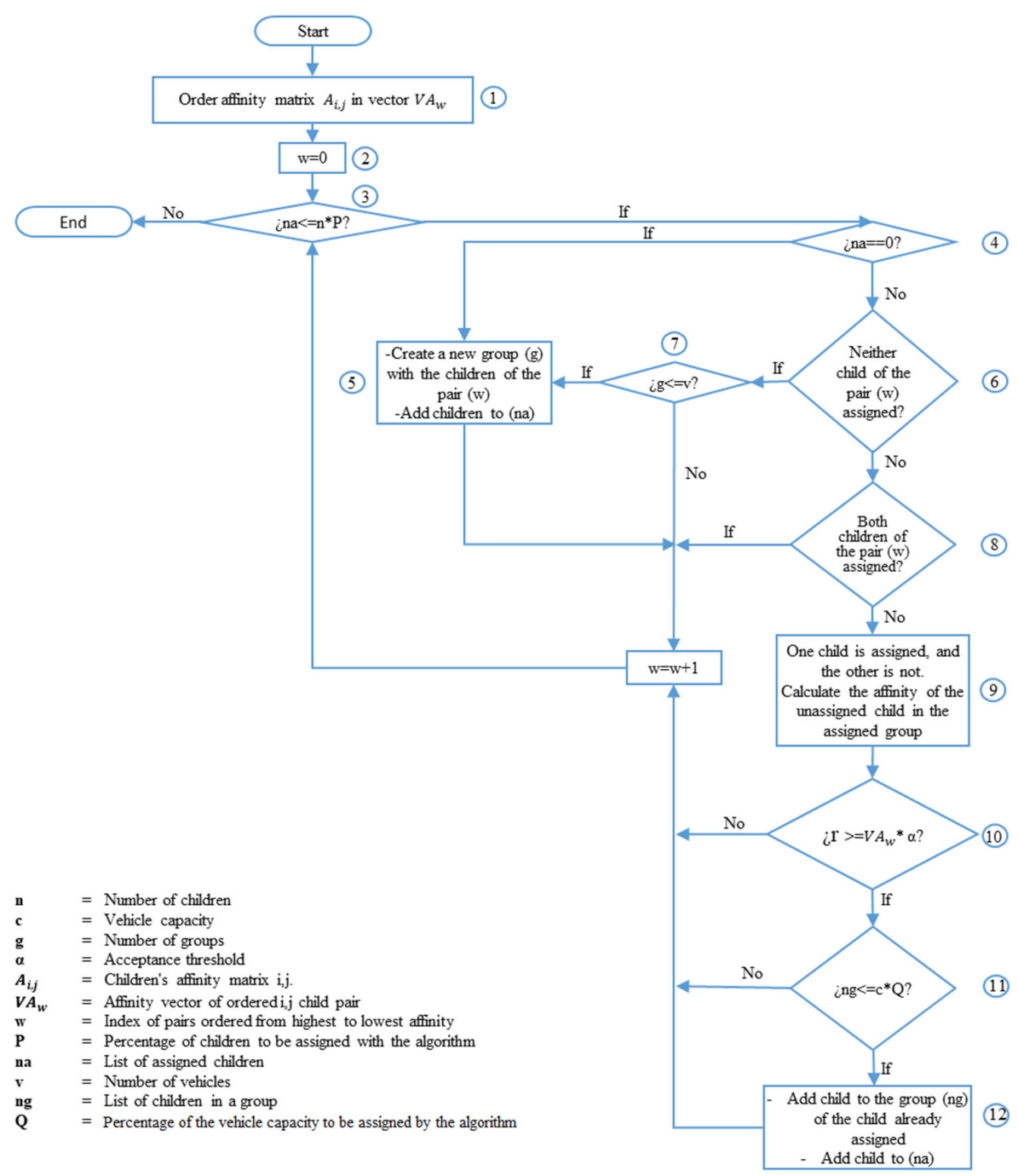

Fig. 5. Algorithm based on group technology for the assignment of children to buses 
The mathematical model seeks to maximize affinity by assigning the remaining children, and the children already assigned enter as parameters and are imposed as constraints by a script. Next, the mathematical formulation of the model is presented.

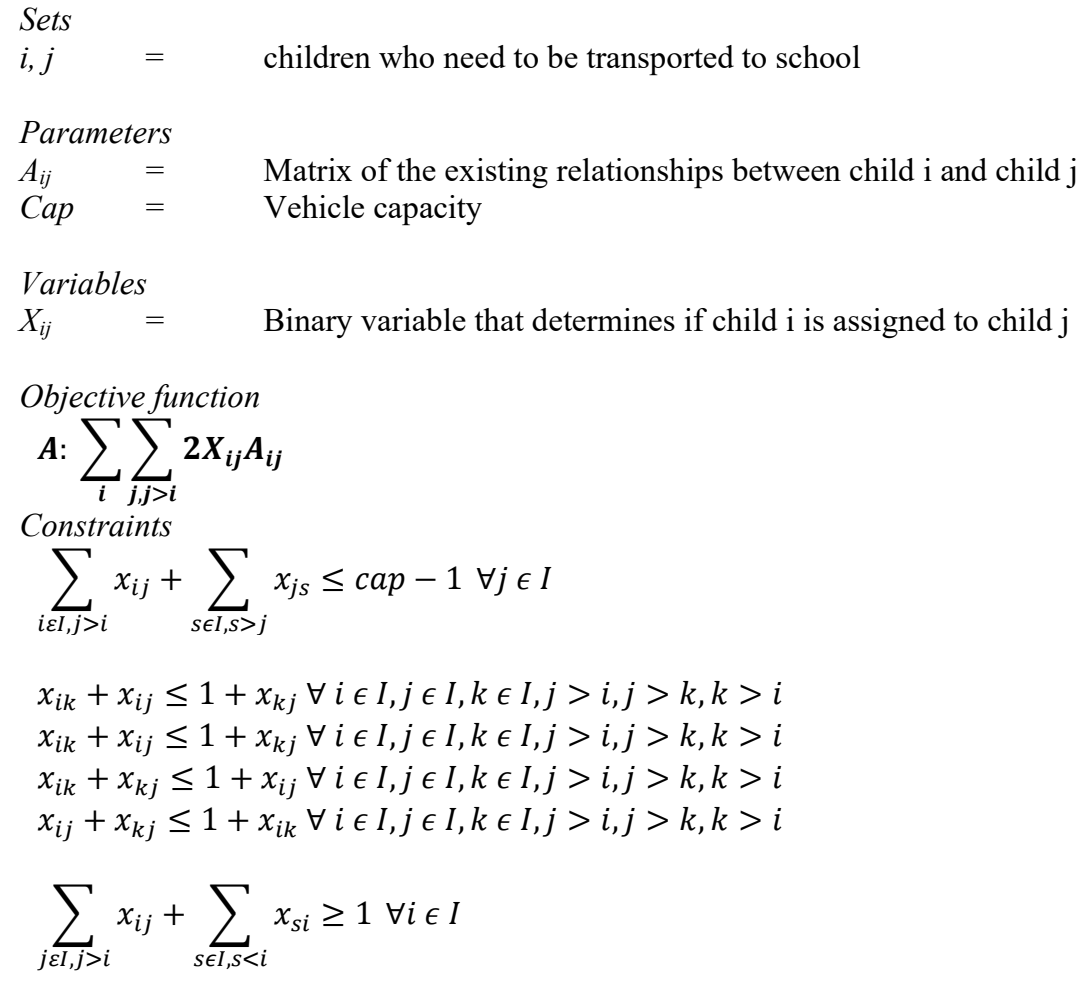

The objective function is presented in Eq. (2), in which the affinity of children is maximized. Constraint (3) guarantees that the number of children who were assigned to the same group does not exceed the capacity of the vehicle. Constraints (4), (5), (6), and (7) guarantee that there is an arc of transitive connection between the children. Constraint (8) allows all children to be assigned to at least one other child.

\subsection{Phase 2. Vehicle routing}

To determine the best route for each bus $\mathrm{k}$, the generalized mathematical model for the TSP solution for each group of children, which is proposed in (Miller et al., 1960), is used. In this model, for each vehicle, the distance between the routes from stop i to stop $\mathrm{j}$ is minimized, ensuring that all stops are visited without sub-tours.

\section{Results}

To validate the proposed methodology, a case study is conducted in the city of Cali, in which there are 170 children who must be transported to school, for which there are 12 vehicles (buses) with a 15-seat capacity each.

\subsection{Phase 1. Assignment of children to vehicles}

\subsubsection{Definition of the affinity between children}

The children evaluate their affinity with each of their classmates on a scale of 1-9. For each pair of children, the two affinities are obtained, and from them, the lowest is taken. The scores are consolidated, and a symmetric $170 \times 170$ quadratic matrix of affinities is obtained.

\subsubsection{Assignment of children to school buses}

\subsubsection{Assignment using the group technology algorithm}

Table 2 shows the assignments using the GT algorithm, which are obtained with $90 \%$ of the total children to be assigned and where the number of children assigned in a vehicle should not exceed $70 \%$ of vehicle capacity to ensure balanced vehicle assignments. 
Table 2

Assignment of children to vehicles by the group technology algorithm

\section{Vehicle}

\begin{tabular}{|ccc|}
\hline $\mathbf{1}$ & 1 & 4 \\
$\mathbf{2}$ & 2 & 29 \\
$\mathbf{3}$ & 3 & 13 \\
$\mathbf{4}$ & 5 & 7 \\
$\mathbf{5}$ & 6 & 8 \\
$\mathbf{6}$ & 9 & 15 \\
$\mathbf{7}$ & 10 & 20 \\
$\mathbf{8}$ & 14 & 24 \\
$\mathbf{9}$ & 16 & 45 \\
$\mathbf{1 0}$ & 17 & 66 \\
$\mathbf{1 1}$ & 18 & 67 \\
$\mathbf{1 2}$ & 19 & 31 \\
\hline
\end{tabular}

\section{Children}

Number of children assigned

\subsubsection{Proposed optimization model for the assignment of children}

After assigning some of the children, the remaining children are assigned with the mathematical model, where those that are already assigned are a parameter, imposing constraints with the groups already created, yielding the results shown in Table 3.

Table 3

Assignment of children to vehicles with the mathematical model

\begin{tabular}{|c|c|c|c|c|c|c|c|c|c|c|c|c|}
\hline Vehicle & 1 & 2 & 3 & 4 & 5 & 6 & 7 & 8 & 9 & 10 & 11 & 12 \\
\hline \multirow{4}{*}{ Children } & 56 & 74 & 82 & 71 & 35 & 76 & 72 & 108 & 43 & & & 54 \\
\hline & 132 & 151 & 101 & 89 & 60 & 128 & 138 & 116 & 153 & & & 63 \\
\hline & 141 & & 107 & 114 & 91 & 144 & 150 & 162 & 163 & & & 69 \\
\hline & 170 & & 168 & 154 & 103 & 152 & 165 & 166 & 167 & & & 97 \\
\hline Number of children assigned & 4 & 2 & 4 & 4 & 4 & 4 & 4 & 4 & 4 & 0 & 0 & 4 \\
\hline
\end{tabular}

The mathematical model assigns the remaining 38 children, grouping the children according to the affinity and the remaining vehicle capacity. The results obtained are presented in Table 4 . A total of 12 groups are generated since there are 12 vehicles, with a maximum occupancy of 15 children per bus and a minimum of 11 children per bus. The lowest affinity is 664 , corresponding to a small group, and the highest is 1452 , corresponding to a large group of 15 children. The total affinity of this assignment is 14770 , and the average affinity of the groups is 6 , demonstrating balanced affinities in the groups.

Table 4

Results of the final assignment of children

\begin{tabular}{lcccccccccccccc}
\hline Vehicle & $\mathbf{1}$ & $\mathbf{2}$ & $\mathbf{3}$ & $\mathbf{4}$ & $\mathbf{5}$ & $\mathbf{6}$ & $\mathbf{7}$ & $\mathbf{8}$ & $\mathbf{9}$ & $\mathbf{1 0}$ & $\mathbf{1 1}$ & $\mathbf{1 2}$ & Total \\
\hline $\begin{array}{c}\text { Vehicle } \\
\text { Affinity }\end{array}$ & 1428 & 1042 & 1342 & 1404 & 1408 & 1344 & 1452 & 1354 & 1272 & 664 & 694 & 1366 & $\mathbf{1 4 7 7 0}$ \\
$\begin{array}{c}\text { Number } \\
\text { of } \\
\text { children } \\
\text { assigned }\end{array}$ & 15 & 13 & 15 & 15 & 15 & 15 & 15 & 15 & 15 & 11 & 11 & 15 & $\mathbf{1 7 0}$ \\
$\begin{array}{c}\text { Average } \\
\text { affinity }\end{array}$ & 6 & 6 & 6 & 6 & 6 & 6 & 6 & 6 & 6 & 5 & 6 & 6 & $\mathbf{6}$ \\
\hline
\end{tabular}

Fig. 6 shows the spatial point distribution of the location of the children, and the arrows indicate the children who were assigned to each group and/or vehicles. 

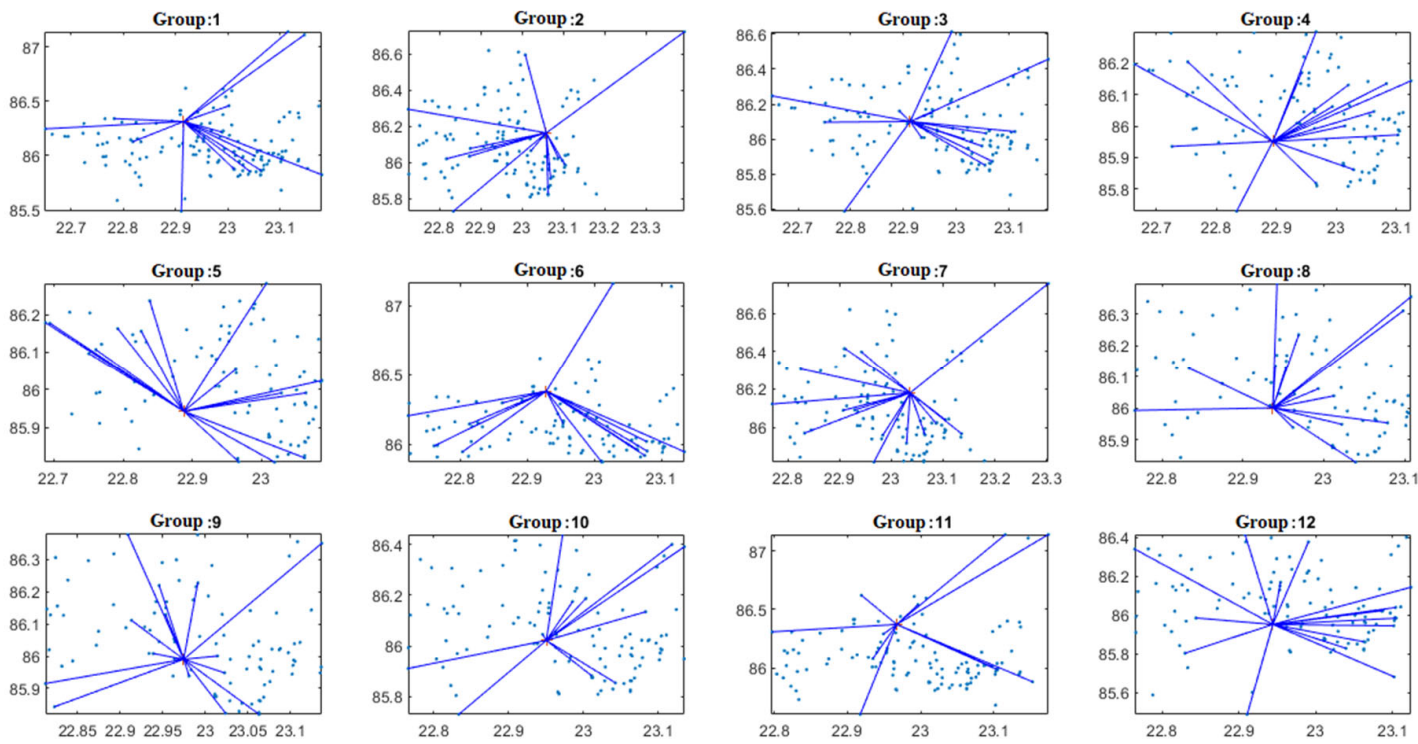

Fig. 6. Assignment of the children to groups

\subsection{Phase 2. Vehicle routing}

The resulting TSPs are modeled and resolved in a script implemented in Java using the ILOG CPLEX library, and the results obtained are presented in Table 5. The routes are shown in Fig. 7. There are 12 routes, including the school; in this case, this school is the point of departure and arrival for each of the vehicles.

Table 5

Distances traveled by each vehicle

\begin{tabular}{cccccccc}
\hline Vehicle & $\mathbf{1}$ & $\mathbf{2}$ & $\mathbf{3}$ & $\mathbf{4}$ & $\mathbf{5}$ & $\mathbf{6}$ & \\
\cline { 1 - 7 } Distance traveled (m) & 38781.33 & 29394.28 & 28690.13 & 20731.71 & 19460.99 & 36998.11 & \\
Vehicle & 7 & 8 & 9 & 10 & 11 & 12 & Total \\
\hline Distance traveled (m) & 29704.33 & 21133.7 & 20733.82 & 19998.17 & 35152.07 & 22823.85 & 323603.5 \\
\hline
\end{tabular}
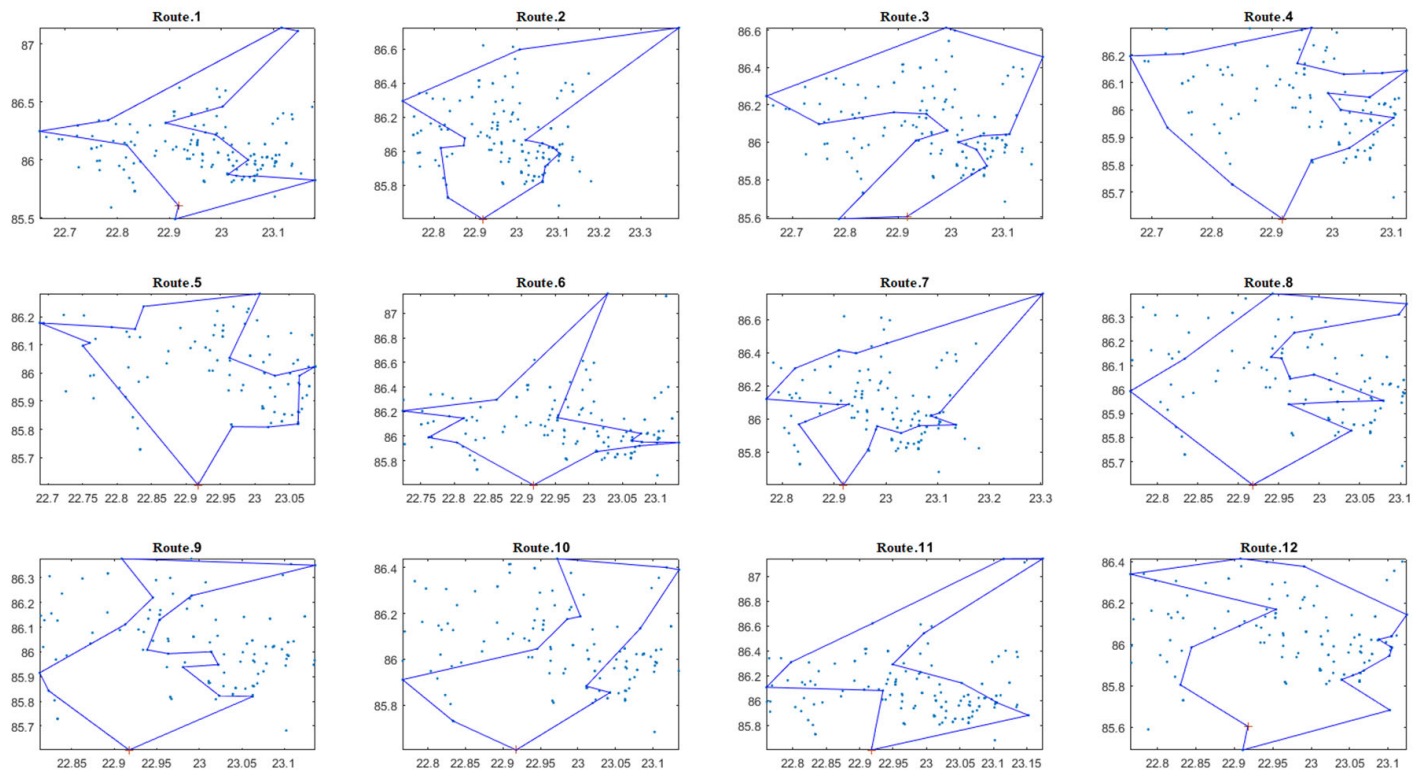

Fig. 7. Vehicle routing 
Regarding the computational times obtained with the developed proposal (see Table 6), the clustering algorithm yields minimal time variability, while the exact model presents more variability, given that 10 of the 12 scenarios take less than $133 \mathrm{~s}$ and two exceed $4500 \mathrm{~s}$ when the $\%$ of children to be assigned to each group is $70 \%$. The average model routing time is higher when the \% of children to be assigned using the GT algorithm is $95 \%$ and the $\%$ of children to be assigned to each group is $95 \%$, equivalent to $221.92 \mathrm{~s}$ on average.

Table 6

Computational times

Computational times in seconds

\begin{tabular}{|c|c|c|c|c|c|c|c|c|c|c|c|c|}
\hline \multirow{2}{*}{$\begin{array}{c}\text { \% Children assigned by } \\
\text { the GT algorithm } \\
\% \text { Of children to be } \\
\text { assigned to each group }\end{array}$} & \multicolumn{6}{|c|}{$95 \%$} & \multicolumn{6}{|c|}{$90 \%$} \\
\hline & $95 \%$ & $90 \%$ & $85 \%$ & $80 \%$ & $75 \%$ & $70 \%$ & $95 \%$ & $90 \%$ & $85 \%$ & $80 \%$ & $75 \%$ & $70 \%$ \\
\hline Clustering algorithm & 0.09 & 0.09 & 0.11 & 0.10 & 0.10 & 0.10 & 0.10 & 0.10 & 0.09 & 0.11 & 0.11 & 0.11 \\
\hline Exact model & 4.50 & 5.02 & 89.31 & 104.53 & 81.81 & 4698.33 & 133.80 & 63.11 & 84.30 & 98.89 & 83.36 & 4635.88 \\
\hline Average routing time & 221.92 & 46.15 & 10.93 & 21.73 & 84.23 & 2.03 & 25.88 & 21.81 & 10.52 & 20.96 & 84.71 & 1.88 \\
\hline
\end{tabular}

\section{Analysis of the results}

\subsection{Variation in assignment percentages}

To assess the impact of the assignment percentage of the GT algorithm on the results of the mathematical model, different scenarios are created by modifying the percentages of assignment by the GT algorithm and the percentage of the vehicle capacity to be assigned by the algorithm. It was found that for $90 \%$ of the total children to be assigned by the GT algorithm (P) and the constraint that no more than $90 \%$ of the vehicle capacity to be assigned to each group (Q), the maximum number of children to be assigned by the GT algorithm is 153 , while for $95 \%$ of the total children, it is 162 , as shown in Table 7 . For the case of $\mathrm{P}$ equal to $90 \%$, it is evidenced that when Q goes from $90 \%$ to $70 \%$, the maximum total number of children to be assigned by the group technology algorithm decreases, from 153 to 126 children, because constraint on Q becomes stronger than the constraint on P; something similar happens when $\mathrm{P}$ is equal to $95 \%$. Since the real total number of children to be assigned depends on Q and not on P. It is for this reason that there are no variations in affinity when P corresponds to $95 \%$ and $90 \%$, for Q percentages of $80 \%, 75 \%$ and $70 \%$, the affinity being 14424,14424 and 14770 respectively (See Table 8).

Table 7

Determination of the net number of children to be assigned by the GT algorithm

\begin{tabular}{|c|c|c|c|}
\hline \multirow[t]{3}{*}{$\begin{array}{c}\text { \% of the vehicle capacity to be assigned by } \\
\text { the GT algorithm (Q) }\end{array}$} & \multirow[t]{3}{*}{$\begin{array}{l}\text { Total number of children } \\
\text { to be assigned }\end{array}$} & \multicolumn{2}{|c|}{$\begin{array}{c}\text { \% of all children to be assigned by } \\
\text { the GT algorithm (P) }\end{array}$} \\
\hline & & $90 \%$ & $90 \%$ \\
\hline & & 153 & 153 \\
\hline $90 \%$ & 162 & 153 & 153 \\
\hline $85 \%$ & 153 & 153 & 153 \\
\hline $80 \%$ & 144 & 144 & 144 \\
\hline $75 \%$ & 135 & 135 & 135 \\
\hline $70 \%$ & 126 & 126 & 126 \\
\hline
\end{tabular}

Table 8

Affinity by percentage of assignment

\begin{tabular}{|c|c|c|c|}
\hline \multirow{2}{*}{\multicolumn{2}{|c|}{ Affinity }} & \multicolumn{2}{|c|}{ \% children to be assigned by the GT algorithm (P) } \\
\hline & & $95 \%$ & $90 \%$ \\
\hline \multirow{5}{*}{ 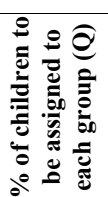 } & $90 \%$ & 14314 & 14688 \\
\hline & $85 \%$ & 14288 & 14384 \\
\hline & $80 \%$ & 14424 & 14424 \\
\hline & $75 \%$ & 14424 & 14424 \\
\hline & $70 \%$ & 14770 & 14770 \\
\hline
\end{tabular}

Table 7 identifies that in the scenarios where the strongest constraint is the total percentage of total children to be assigned to the group, the affinity increases as the percentage of child assignment decreases, which is explained by the fact that the mathematical model of assignment has more decision variables to optimize. However, this contrasts with the computational time required by the model (see Fig. 8). 


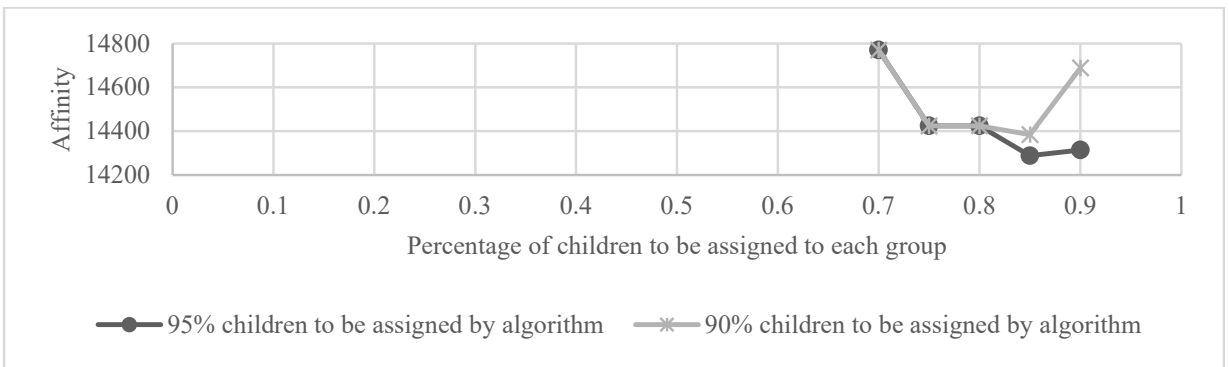

Fig. 8. Affinity trend by assignment percentage

\subsection{Comparison of the results of the grouping considering affinity with multisweep grouping that considers the distance traveled}

With the purpose of identifying the trade-off in costs due to the improvement in affinity, the results obtained from the proposal of assigning children to vehicles considering affinity are compared below, presenting the assignment results in which only the distance traveled is considered using the multisweep algorithm based on the proposal made in (Gillett \& Miller, 1974b).

Table 9 shows the assignments of children to vehicles obtained through the application of the multisweep assignment algorithm. The largest group consists of 15 children, and the smallest group consists of five children. In addition, the highest group affinity corresponds to 1188 and the lowest to 124, with a total affinity of 12536 and an average of 5.01 for all groups. Fig. 9 shows the routes obtained for picking up all the children.

Table 9

Indicators of the assignment of children with the multisweep algorithm

\begin{tabular}{|c|c|c|c|c|}
\hline Vehicle & Affinity & $\begin{array}{c}\text { Distance traveled } \\
(\mathbf{m})\end{array}$ & $\begin{array}{c}\text { Number of children } \\
\text { assigned }\end{array}$ & Average affinity \\
\hline 1 & 1136 & 9757.44 & 15 & 5.05 \\
\hline 2 & 1112 & 9669.60 & 15 & 4.94 \\
\hline 3 & 1258 & 25070.57 & 15 & 5.59 \\
\hline 4 & 1188 & 24404.55 & 15 & 5.28 \\
\hline 5 & 1004 & 16691.24 & 15 & 4.46 \\
\hline 6 & 1090 & 31776.32 & 15 & 4.84 \\
\hline 7 & 1214 & 31277.92 & 15 & 5.40 \\
\hline 8 & 1096 & 20518.66 & 15 & 4.87 \\
\hline 9 & 1138 & 17031.46 & 15 & 5.06 \\
\hline 10 & 1072 & 16034.65 & 15 & 4.76 \\
\hline 11 & 1104 & 14288.32 & 15 & 4.91 \\
\hline 12 & 124 & 5723.76 & 5 & 4.96 \\
\hline Total & 12536 & 222244.49 & 170 & 5.01 \\
\hline
\end{tabular}
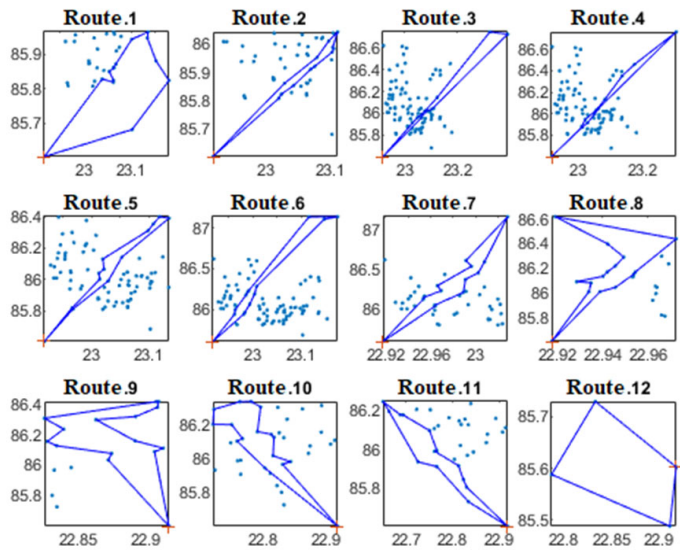

Fig. 9. Routes per vehicle with the multisweep algorithm 


\subsection{Comparison of the grouping results considering a routing - assignment strategy}

The results obtained are compared using a routing-assignment strategy to identify the trade-off between the costs of improving the affinity and minimizing the distance traveled. First, all nodes are routed through a TSP with the CPLEX solver, then the route is segregated considering the vehicle capacity constraints, and the affinity for each route is obtained.

Table 10 shows that ten groups of 14 children are assigned to vehicles and that two groups of 15 children are assigned, where the highest affinity corresponds to 1060 and the lowest 858, allowing for a total of 11498, with an average affinity of 4.78 .

\section{Table 10}

Indicators of the assignment of children for the routing - assignment strategy

\begin{tabular}{ccccc}
\hline Vehicle & Affinity & Distance traveled (m) & $\begin{array}{c}\text { Number of } \\
\text { children assigned }\end{array}$ & Average affinity \\
\hline $\mathbf{1}$ & 1054 & 12428.46 & 15 & 4.68 \\
$\mathbf{2}$ & 988 & 13053.06 & 15 & 4.39 \\
$\mathbf{3}$ & 946 & 15893.27 & 14 & 4.83 \\
$\mathbf{4}$ & 980 & 20117.88 & 14 & 5.00 \\
$\mathbf{5}$ & 984 & 34285.14 & 14 & 5.02 \\
$\mathbf{6}$ & 862 & 34910.29 & 14 & 4.40 \\
$\mathbf{7}$ & 912 & 14836.93 & 14 & 4.65 \\
$\mathbf{8}$ & 1060 & 10373.82 & 14 & 5.41 \\
$\mathbf{9}$ & 858 & 10745.67 & 14 & 4.38 \\
$\mathbf{1 0}$ & 892 & 10922.30 & 14 & 4.55 \\
$\mathbf{1 1}$ & 904 & 7899.21 & 14 & 4.61 \\
\hline $\mathbf{1 2}$ & 1058 & 9593.54 & 14 & 5.40 \\
\hline Total & 11498 & 195059.58 & 170 & 4.78 \\
\hline
\end{tabular}

Table 11 shows the results of the affinity and total distance traveled with the algorithms of the proposed routing considering the affinity, routing with multisweep, and the routing-assignment strategy. It is evident that the assignment of children considering affinity yields a longer distance traveled than the other two strategies, but this grouping generates the highest affinity.

\section{Table 11}

Grouping comparisons

\begin{tabular}{lcc}
\multicolumn{1}{c}{ Routing } & Total affinity & Total distance traveled (m) \\
\hline Considering affinity & 14470 & 323602.50 \\
Multisweep & 12536 & 222244.49 \\
Routing-assignment & 11498 & 195959.58 \\
\hline
\end{tabular}

The route provided by the affinity algorithm yields a child affinity that is $15 \%$ higher than that of the multisweep algorithm but a $46 \%$ longer total distance. This suggests that these two objectives need to be balanced. Additionally, the algorithm that considers the affinity yields a child affinity that is $25.8 \%$ higher than that of the routing-assignment strategy but a $65.13 \%$ longer total route distance.

\section{Conclusions}

Social aspects have been minimally studied in the SBRP; in this sense, this work proposes the affinity between students as a mechanism to strengthen the positive interactions of children, to encourage supportive behaviors in bullying situations, and to improve the well-being of the children along the route. In addition, in the frame of reference, bullying extends beyond school limits, including school transportation, so addressing the problem of affinity between children in the process of school bus routing constitutes a new variant to develop in this knowledge field.

The proposed methodology integrates, on the one hand, the affinity in the SBRP and presents a series of steps the complexity of the problem to be addressed since heuristic elements are combined with optimization strategies, and decomposition into subproblems mitigates the complexity of the original problem. Additionally, the methodology proposes a group technology algorithm and a new mathematical model that linearizes the classical QAP model, both simplify the problem and allow to solve appropriate assignment instances according to the context affinity in the SBRP. 
Finally, it is important to emphasize that considering affinity generates benefits from a social point of view, which should be borne in mind when evaluating the increase in transportation costs. For example, in the case study, a $15 \%$ increase in affinity is associated with a $46 \%$ increase in the total distance traveled, which suggests that in future research, multiple objectives that ensure a balance between the different metrics should be considered.

\section{Acknowledgments}

The authors thank the support of the Universidad del Valle.

\section{References}

Aiko, S., Thaithatkul, P., \& Asakura, Y. (2018). Incorporating user preference into optimal Vehicle Routing Problem of integrated sharing transport system. Asian Transport Studies, 5(issue 1), 98-116. https://doi.org/10.11175/eastsats.5.98

Brusco, M.J., \& Köhn, H. (2008). Optimal Partitioning of a Data Set Based on the p-Median Model. Psychometrika, 73,89. https://doi-org.bd.univalle.edu.co/10.1007/s11336-007-9021-4

Clarke, G., \& Wright, J. W. (1964). Scheduling of vehicles from a central depot to a number of delivery points. Operations Research, 12(4), 568-581.

Comert, S. E., Yazgan, H. R., Kır, S., \& Yener, F. (2018). A cluster first-route second approach for a capacitated vehicle routing problem: A case study. International Journal of Procurement Management, 11(4), $399-419$. https://doi.org/10.1504/IJPM.2018.092766

Craig, W. M., \& Pepler, D. J. (2007). Understanding bullying: From research to practice. Canadian Psychology, 48(2), 8693. https://doi.org/10.1037/cp2007010

Duque Correa, A. F., \& Baldoquín de la Peña, M. G. (2018). Solving the assignment of customers to trucks and visit days in a periodic routing real-world case1. Ingenieria y Universidad, 22(1), 53-76. https://doi.org/10.11144/Javeriana.iyu22-1.sact

Ellegood, W. A., Solomon, S., North, J., \& Campbell, J. F. (2019). School bus Routing Problem: Contemporary Trends and Research Directions. Omega. https://doi.org/10.1016/j.omega.2019.03.014

Emilia, R., \& Emilia, R. (1983). • Route First-Cluster Second Introduzione. I(4), 0-5.

Galliger, C. C., Tisak, M. S., \& Tisak, J. (2009). When the wheels on the bus go round: Social interactions on the school bus. Social Psychology of Education, 12(1), 43-62. https://doi.org/10.1007/s11218-008-9072-0

Gillett, B. E., \& Miller, L. R. (1974a). A Heuristic Algorithm for the Vehicle-Dispatch Problem. August 2015.

Gillett, B. E., \& Miller, L. R. (1974b). A Heuristic Algorithm for the Vehicle-Dispatch Problem. Operations Research, 22(2), 340-349.

Giosa, I. D., Tansini, I. L., \& Viera, I. O. (2017). New assignment algorithms for the multi-depot vehicle routing problem New assignment algorithms for the multi-depot vehicle routing problem. 5682. https://doi.org/10.1057/palgrave.jors.2601426

Goldman, S., \& Peleg, K. (2010). Pupil behaviour on school buses and potential risk factors for injury : an observational study. Bull World Health Organ, 88(February), 570-575. https://doi.org/10.2471/BLT.08.058396

Goodboy, A. K., Martin, M. M., \& Brown, E. (2016). Bullying on the school bus : deleterious effects on public school bus drivers. Journal of Applied Communication Research, 44(4), 434-452. https://doi.org/10.1080/00909882.2016.1225161

Gutierrez, I. A., \& Ñopo, H. (2018). Stand Against Bullying: An Experimental School Intervention Stand Against. IZA Institute of Labor Economics, 11623, 51.

Jiménez, J. de la C. (2018). Bullying por orientación sexual entre estudiantes masculinos. Criterio Libre, 28, $205-219$.

Kalpakjian, S., \& Steven, R. (2008). Libro Tecnología de grupos.pdf(Pearson (ed.)).

Kasirzadeh, A., Saddoune, M., \& Soumis, F. (2017). Airline crew scheduling : models , algorithms , and data sets. EURO Journal on Transportation and Logistics, 6(2), 111-137. https://doi.org/10.1007/s13676-015-0080-x

Kohl, N., \& Karisch, S. E. (2004). Airline Crew Rostering: Problem Types, Modeling and Optimization. Annals of Operations Research, 127, 223-257.

Kumar, V., Bierlaire, M., \& Gallay, O. (2010). Generalized Algorithms for Crew Planning : Survey and Future Directions for Railways. STRC, September.

Lin, H., Chen, Y., Chou, T., \& Liao, Y. (2012). Crew rostering with multiple goals : An empirical study. COMPUTERS \& INDUSTRIAL ENGINEERING, 63(2), 483-493. https://doi.org/10.1016/j.cie.2012.04.013

Long, J., Harré, N., \& Atkinson, Q. (2015). Social clustering in high school transport choices. Journal of Environmental Psychology, 41, 155-165. https://doi.org/10.1016/j.jenvp.2015.01.001

MacQueen, J., \& Others. (1967). Some methods for classification and analysis of multivariate observations. Proceedings of the Fifth Berkeley Symposium on Mathematical Statistics and Probability, 1(14), 281-297.

Meskens, N., Duvivier, D., \& Hanset, A. (2013). Multi-objective operating room scheduling considering desiderata of the surgical team. Decision Support Systems, 55(2), 650-659. https://doi.org/10.1016/j.dss.2012.10.019

Miller, C. E., Tucker, A. W., \& Zemlin, R. A. (1960). Integer Programming Formulation of Traveling Salesman Problems. J. ACM, 7(4), 326-329. https://doi.org/10.1145/321043.321046 
Miranda-Bront, J. J., Curcio, B., Méndez-Díaz, I., Montero, A., Pousa, F., \& Zabala, P. (2017). A cluster-first route-second approach for the swap body vehicle routing problem. Annals of Operations Research, 253(2), 935-956. https://doi.org/10.1007/s10479-016-2233-1

Quintero Quintero, T. (2012). ALGORITMO HÍBRIDO BASADO EN UN MÉTODO DE APROXIMACIONES SUCESIVAS PARA EL PROBLEMA DE RUTEO DE VEHÍCULOS HETEROGÉNEO.

Raskauskas, J. (2005). Bullying on the school bus: A video analysis. Journal of School Violence, 4(3), 93-107. https://doi.org/10.1300/J202v04n03_08

Saaty, R. W. (1987). The analytic hierarchy process-what it is and how it is used. Mathematical Modelling, 9(3-5), 161176. https://doi.org/10.1016/0270-0255(87)90473-8

Sarubbi, J. F., Mesquita, C. M., Wanner, E., Santos, V. F., \& Silva, C. M. (2016). A strategy for clustering students minimizing the number of bus stops for solving the school bus routing problem. In C. C. G. L. Z. dos S. C. R. P. Badonnel S.O. Ulema M. (Ed.), Proceedings of the NOMS 2016 - 2016 IEEE/IFIP Network Operations and Management Symposium (pp. 1175-1180). Institute of Electrical and Electronics Engineers Inc. https://doi.org/10.1109/NOMS.2016.7502983

Sule, D. R. (2001). Instalaciones de manufactura: ubicación, planeación y diseño. Thomson.

Thaithatkul, P., Seo, T., Kusakabe, T., \& Asakura, Y. (2015). A passengers Matching Problem in ridesharing systems by considering user preference. Journal of the Eastern Asia Society for Transportation Studies, 11, 1416-1432. https://doi.org/10.11175/easts.11.1416

UNESCO. (2018). School violence and bullying: Global status and trends, drivers and consequences.

UNESCO. (2019). Behind the numbers: Ending school violence and bullying.

Unsal, O., Yigit, T., \& Altintas, C. (2016). Optimization of Dynamic School Bus Routing Problem by Using Metaheuristic and Clustering Methods. Proceedings of the 11th International Confenference on Practice and Theory of Auto-Mated Timetabling (PATAT-2016) -Udine, Italy, August 23-26, 2016, 555-559.

Waygood, E. O. D., Friman, M., Taniguchi, A., \& Olsson, L. E. (2019). Children's life satisfaction and travel satisfaction : Evidence from Canada, Japan, and Sweden. Travel Behaviour and Society, 16(April 2018), $214-223$. https://doi.org/10.1016/j.tbs.2018.04.004

White, J. (2019). Addressing school violence and bullying : Evidence review. NHS Health Scotland.

Zhou, J., Love, P. E. D., Teo, K. L., \& Luo, H. (2017). An exact penalty function method for optimising QAP formulation in facility layout problem. International Journal of Production Research, 55(10), $2913-2929$. https://doi.org/10.1080/00207543.2016.1229068 


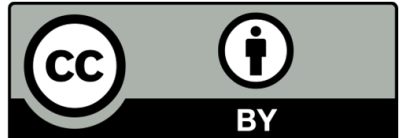

(C) 2021 by the authors; licensee Growing Science, Canada. This is an open access article distributed under the terms and conditions of the Creative Commons Attribution (CC-BY) license (http://creativecommons.org/licenses/by/4.0/). 